\title{
Glycemic Control in Medical Inpatients with Type 2 Diabetes Mellitus Receiving Sliding Scale Insulin Regimens versus Routine Diabetes Medications: A Multicenter Randomized Controlled Trial
}

Lori M. Dickerson, PharmD, BCPS

Xiaobu Ye, MS

Jonathan L. Sack, $M D^{1}$

William J. Hueston, $M D^{1}$

${ }^{1}$ Department of Family Medicine, Medical University of South Carolina, Charleston, SC

${ }^{2}$ Department of Oncology, Clinical Trials and Biometry, Johns Hopkins University, Baltimore, Md

\begin{abstract}
PURPOSE Hospitalized patients with type 2 diabetes mellitus traditionally receive insulin on a sliding-scale regimen, but the benefits of this approach are unclear. The purpose of this study was to compare the effects of the sliding scale insulin regimen with those of routine diabetes medications on hyperglycemia, hypoglycemia and length of hospitalization in diabetic patients hospitalized for other conditions.

METHODS This was a multicenter, randomized controlled trial conducted in family medicine inpatient services. One hundred fifty-three patients with type 2 diabetes mellitus hospitalized for other conditions were randomized to receive routine diabetes medications (control) or the combination of a standard sliding-scale insulin regimen and routine diabetes medications (intervention). The outcome measures included frequency of hyperglycemia and hypoglycemia (glycemic events), and length of hospitalization.
\end{abstract}

RESULTS No differences were identified between treatment groups in the frequency of glycemic events. In the intervention group, 33.3\% of patients developed hyperglycemia compared to $34.6 \%$ in the control group $(P=.87)$. Six patients developed hypoglycemia in the intervention group, compared with 7 in the control group $(P=.83)$. There was no difference in length of hospitalization $(P=.86)$. Regardless of treatment assignment, patients receiving intermediate-acting insulin (OR, 2.8; 95\% Cl, 1.2-6.5), those with blood glucose values greater than 250 $\mathrm{mg} / \mathrm{dL}$ at baseline (OR, 6.3; $95 \% \mathrm{Cl}, 2.3-17.2)$ and those receiving corticosteroids (OR, 9.1; $95 \% \mathrm{Cl}, 3.1-27.0)$ were more likely to have glycemic events.

CONCLUSIONS The use of the sliding scale insulin regimen in combination with routine diabetes medications does not affect the rate of hyperglycemia, hypoglycemia or length of hospitalization in patients with type 2 diabetes mellitus hospitalized for other conditions.

Ann Fam Med 2003;1:29-35. DOI: 10.1370/afm.2

\section{INTRODUCTION}

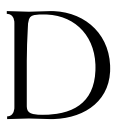
iabetes mellitus (DM) is a common comorbid condition in hospitalized patients. Traditionally, patients with type 2 DM are converted from their routine diabetes medications to a sliding scale insulin (SSI) regimen or receive the SSI in addition to their routine dia- 
betes medications during hospitalization. ${ }^{1,2}$ The SSI regimen consists of short-acting insulin 4 to 6 times a day, based on regularly obtained capillary blood glucose measurements. In the face of metabolic stressors, other acute medical conditions, and varying diet and activity levels, the SSI is used in belief that this regimen is better able to maintain tight glycemic control and avoid glycemic events (ie, hypoglycemia and hyperglycemia). It is not clear how this practice began, but it has become a popular method of glucose control usually learned during residency training. ${ }^{1}$ For example, in a study of medical inpatients, physicians prescribed an SSI regimen for $61 \%$ of patients with type 2 DM who were admitted to the hospital for reasons other than metabolic control. ${ }^{3}$

There are several problems associated with the use of the SSI regimen, however. ${ }^{1,4-9}$ The regimen typically results in an increase in the number of insulin injections received, and insulin is given retrospectively for high blood glucose values and not given during euglycemia or before anticipated hyperglycemia attributable to concurrent or planned meals. Patients are often awakened during the night for blood glucose monitoring and insulin therapy, which may increase the incidence of nocturnal hypoglycemia. In addition, there is no standard SSI regimen, and dosages vary widely between patients, providers, and institutions.

Furthermore, some evidence suggests that SSI regimens carry additional risk of glycemic events instead of protecting against them. In both retrospective and nonrandomized studies, not only have SSI regimens been associated with an increase in hyperglycemia and hypoglycemia, but they have also been associated with an increased length of stay for hospitalized diabetic patients. $3,7,10,11$ Additionally, there is no evidence to suggest any short- or long-term benefit from tight glycemic control during hospitalization for most comorbid medical conditions. Although hyperglycemia has theoretical effects on granulocyte adhesion, chemotaxis, phagocytosis, etc, and has demonstrable effects on glycosuria and dehydration, these effects have not been studied in prospective clinical trials to demonstrate adverse consequences. ${ }^{12}$ While tight glycemic control with insulin and glucose infusions has been associated with reductions in mortality in patients with acute myocardial infarction and reductions in morbidity and mortality in critically ill patients in the intensive care unit setting, there is no known benefit from tight glycemic control during hospitalization for many other illnesses. ${ }^{13,14}$

Given all this, the use of the SSI regimen has come under increased scrutiny in the management of medical inpatients with type $2 \mathrm{DM}$. Considering the frequency of use of SSI regimens in patients with type 2 DM and comorbid conditions and the type and results of published studies examining their effect on glycemic control, we conducted a prospective, randomized controlled trial to evaluate the addition of the SSI regimen to routine diabetes medications in terms of its effects on glycemic events and length of hospitalization in patients with type 2 DM hospitalized for other comorbid illnesses.

\section{METHODS}

\section{Patients}

This was a multicenter, randomized controlled trial in which patients were enrolled from the inpatient services of 10 family medicine residency programs across the United States. A convenience sample of adults admitted to the inpatient services with a comorbid illness and a concurrent diagnosis of type 2 DM were evaluated for study eligibility, and all patients were enrolled within 12 hours of admission. Patients were excluded from enrollment in the presence of diabetic ketoacidosis (DKA), hyperosmolar nonketotic state or hypoglycemia on admission, ${ }^{15}$ pregnancy; acute myocardial infarction ${ }^{13}$; hemodynamic instability attributable to hypovolemia, dehydration or significant blood loss; or acute cerebrovascular accident. All assessments of exclusion criteria were based on clinical judgment, although the following American Diabetes Association definitions were provided:

- DKA: blood glucose greater than $250 \mathrm{mg} / \mathrm{dL}$ $(13.8 \mathrm{mmol} / \mathrm{L})$ with arterial $\mathrm{pH}$ less than 7.35 or venous $\mathrm{pH}$ less than 7.30 or serum bicarbonate level less than $15 \mathrm{mEq} / \mathrm{L}(15 \mathrm{mmol} / \mathrm{L})$ and ketonuria and/or ketonemia

- Hyperosmolar nonketotic state: blood glucose greater than $400 \mathrm{mg} / \mathrm{dL}(22.2 \mathrm{mmolL})$ and plasma osmolality greater than $315 \mathrm{mOsm} / \mathrm{kg}$ and/or impaired mental status

- Hypoglycemia: blood glucose less than $50 \mathrm{mg} / \mathrm{dL}$ $(2.8 \mathrm{mmol} / \mathrm{L})$ where the treatment of hypoglycemia has not resulted in the complete recovery of sensori$\mathrm{um}_{i}$ or coma, seizures or altered behavior (eg, disorientation, ataxia, unstable motor coordination, dysphagia) due to documented hypoglycemia

Finally, patients were excluded if they were less than 18 years of age, were unable to take food or medications by mouth, or the investigators were unable to obtain informed consent from patient or caregiver.

\section{Treatment}

If eligible, the patient was invited to participate and informed consent was obtained by the study coordinator at each site. Once informed consent was obtained, treat- 


\begin{tabular}{|ccc|}
\hline \multicolumn{3}{|c|}{ Table 1. Sliding Scale Insulin Protocol } \\
\hline $\begin{array}{c}\text { Blood } \\
\text { Glucose } \\
\text { (mgldL) }\end{array}$ & $\begin{array}{c}\text { Subcutaneous } \\
\text { Dose of Regular } \\
\text { Human Insulin to be } \\
\text { Administered (units) }\end{array}$ & $\begin{array}{c}\text { Additional } \\
\text { Action Requested }\end{array}$ \\
$0-50$ & 0 & 1 ampule D50, call MD \\
$51-100$ & 0 & 4 oz fruit juice, call MD \\
$101-150$ & 0 & No action \\
$151-200$ & 2 & No action \\
$201-250$ & 4 & No action \\
$251-300$ & 6 & No action \\
$301-350$ & 8 & No action \\
$351-400$ & 10 & No action \\
$>400$ & 12 & Call MD \\
\hline${ }^{*}$ Conversion factor to SI $=0.05551$ & \\
\hline
\end{tabular}

ment assignment was made with the use of sealed envelopes and a randomized complete block design using blocks of 20 subjects. Patients were randomized to receive either the SSI regimen in addition to their routine diabetes medications during hospitalization or their routine diabetes medications only during hospitalization. Routine diabetes medications were deemed to include any oral antidiabetic agent (glipizide, glyburide, metformin, rosiglitazone, acarbose, repaglinide, etc) and any standing dosage of intermediate acting and/or regular insulin (70/30 NPH and regular insulin, etc). A conservative SSI regimen (based on the investigator's local hospital protocol) was used in the intervention group (Table 1). Neither patients nor physicians were blinded to the treatment assignment. In both groups, routine diabetes medications were adjusted, added, or discontinued as they would be during routine care. Both groups received capillary blood glucose measurements four times a day, before meals and at bedtime, and all patients were placed on a standard American Diabetes Association diet on admission. Other interventions, laboratory investigations and special studies were initiated according to the standards of care for DM and comorbid conditions.

Once randomized, patients received treatment according to their group assignment for a minimum of 24 hours. Physicians could not switch the treatment assignment during the study unless clinically indicated, in which case the patient was withdrawn from the study. Patients reached a study endpoint if they developed any of the exclusion criteria (ie, DKA, hyperosmolar nonketotic state hypoglycemia, acute myocardial infarction, etc), if they failed to receive treatment according to their group for a minimum of 24 hours, if they were discharged before 24 hours, or if the patient or physician requested withdrawal.

At baseline, demographic and clinical information was obtained and recorded on a standardized data-col- lection form using unique identifiers to protect patient confidentiality. After hospital discharge, information on glycemic events and length of hospitalization was recorded, as well as information on any patient withdrawal. All information was sent to the principal investigator for centralized data entry and analysis.

The primary outcome measures of interest were the frequency of hyperglycemia greater than 300 $\mathrm{mg} / \mathrm{dL}(16.7 \mathrm{mmol} / \mathrm{L})$, hypoglycemia less than 50 $\mathrm{mg} / \mathrm{dL}(2.8 \mathrm{mmol} / \mathrm{L})$ and glycemic events (combination of hyperglycemia and hypoglycemia). Specific values for hyperglycemia and hypoglycemia were based on definitions from previous clinical trials and consensus statements. ${ }^{11,15}$ A secondary outcome measure was the length of hospitalization.

\section{Statistical Analysis}

The sample size estimate was based on pilot data, which found a $70 \%$ relative reduction in glycemic excursions (combined hyperglycemic and hypoglycemic events) in the group receiving routine diabetes medications when compared with those receiving the combination of routine diabetes medications and the SSI regimen.

Using a more conservative estimate of an effect size of 0.6 to determine a statistically significant difference in the patients with glycemic excursions between groups, the sample size estimate was determined to be a total of 150 with equal allocation (2-sided $\alpha$ level 0.05 , power $90 \%$ ). This sample size was also adequate to determine a statistically significant difference in length of stay, based on data from Gearhart and colleagues. ${ }^{10}$ In order to enroll 150 patients, the initial sample size was overestimated at 200 patients (100 patients in each group, and 20 patients enrolled at each study site) to account for attrition attributable to early discharge, death, physician- or patient-initiated study withdrawal.

Analyses were by intention-to-treat, with the critical level for a 2 -sided test of 0.05 . We used descriptive statistics to assess the baseline characteristics and identify any differences between the treatment groups. We evaluated the primary hypothesis (frequency of hyperglycemia and hypoglycemia) with the Pearson $\chi^{2}$ test. For the difference in total number of glycemic events and length of hospitalization, we used the nonparametric median test because of the skewed nature of the data. We performed a complete univariate analysis to determine statistically and clinically significant variables for the multivariate analysis. We then used multivariate logistic regression to identify independent predictors of hyperglycemic or hypoglycemic events during hospitalization, and no interaction term was formed in the model. This study was approved by the Institu- 


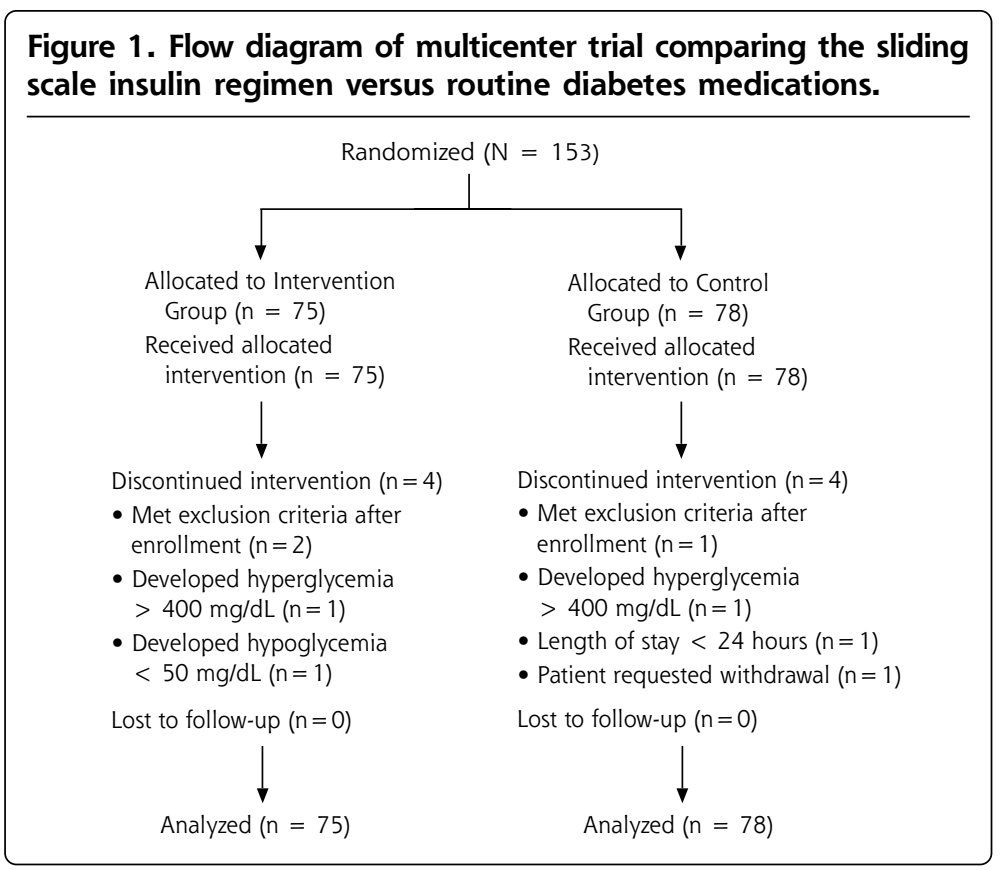

(54.9\%), and significantly more patients in the control group were receiving intermediate acting insulin $50.0 \%$ control group, $33.3 \%$ intervention group, $P=0.04)$. The use of corticosteroids during hospitalization was not different between the groups (20.0\% intervention group, $14.1 \%$ control group, $P=$ $0.33)$. As Figure 1 indicates, 8 patients were withdrawn from the study (4 in each group) for the following reasons:

- Exclusion criteria met after enrollment $(\mathrm{n}=3)$

- Development of hyperglycemia greater than $400 \mathrm{mg} / \mathrm{dL}(22.2$ $\mathrm{mmol} / \mathrm{L})(\mathrm{n}=2)$

- Development of hypoglycemia less than $50 \mathrm{mg} / \mathrm{dL}(2.8 \mathrm{mmol} / \mathrm{L})(\mathrm{n}=1)$

- Length of stay less than 24 hours $(\mathrm{n}=1)$

- Patient's request $(\mathrm{n}=1)$ tional Review Board for Research at the Medical University of South Carolina and at each of the participating study sites (see acknowledgments).

\section{RESULTS}

A total of 153 patients were enrolled in the study between June 2000 and October 2001 (Figure 1). The clinical and demographic characteristics of the treatment groups were similar at randomization (Table 2). The primary reasons for hospitalization included cardiovascular disease $(44.1 \%)$, infection $(10.3 \%)$, pulmonary disease $(8.4 \%)$ and neurological disease $(7.6 \%)$. Of the patients who had admission diagnoses of cardiovascular disease, 19 had chest pain, 14 had congestive heart failure, 4 had atrial fibrillation, and 1 had pulmonary hypertension.

Although patients with acute myocardial infarction (AMI) were excluded from enrollment, patients with chest pain were allowed to enroll in the study until cardiac enzymes clarified the diagnosis, because of the high clinical frequency of noncardiac causes for chest pain. There were no differences in admission diagnoses between the groups. Admission and discharge diagnosis matched in $78.7 \%$ and $68.0 \%$ of patients in the intervention and control groups, respectively $(P=.14)$.

Many patients were receiving combination therapy (ie, oral sulfonylurea and intermediate acting insulin, etc) for glucose control $(43.8 \%)$, and $5.3 \%$ had dietcontrolled diabetes (Table 2). Oral sulfonylurea agents were the most commonly used antidiabetic agents

\section{Primary and Secondary Outcomes}

We detected no differences between the addition of an SSI regimen to routine medications and the use of routine medications alone in frequency of glycemic events or in the length of hospitalization (Table 3 ). Hyperglycemia occurred in approximately one third of patients, and hypoglycemia occurred in about $9 \%$ of patients. There were no statistically significant differences in the severity of hyperglycemia or hypoglycemia between the groups (Table 4), nor were there any clinical consequences in patients experiencing these outcomes. Overall, glycemic events occurred in approximately $36 \%$ of patients, who each had about 1 glycemic event during hospitalization, regardless of treatment assignment. The length of stay was approximately 5 days in both groups.

\section{Secondary Analysis}

Based on the univariate analysis, the following variables were included in the multivariate logistic regression model: treatment assignment, use of corticosteroids during hospitalization, admission blood glucose, diagnosis on admission of cardiovascular or infectious disease, routine diabetes treatment including the use of intermediate acting insulin or combination therapy, and length of stay.

Multivariate analysis identified 3 independent predictors of glycemic events (Table 5). There was a statistically significant increase in glycemic events in patients using intermediate acting insulin as part of their routine diabetes medications, those with baseline blood glucose values greater than $250 \mathrm{mg} / \mathrm{dL}(13.9 \mathrm{mmol} / \mathrm{L})$, and those 


\begin{tabular}{|c|c|c|c|}
\hline Characteristic & $\begin{array}{l}\text { SSI-plus-routine- } \\
\text { medications group } \\
(n=75)\end{array}$ & $\begin{array}{l}\text { Routine- } \\
\text { medications- } \\
\text { only group } \\
(\mathrm{n}=78)\end{array}$ & $P$ value \\
\hline Age, mean (SD), y & $62.5(13.4)$ & $65.9(14.2)$ & .61 \\
\hline Male sex, No. (\%) & $28(37.3)$ & $25(32.1)$ & .49 \\
\hline Race, No. (\%) & & & .64 \\
\hline White, not of Hispanic Origin & $39(52.0)$ & $44(56.4)$ & \\
\hline Black, not of Hispanic Origin & $27(36.0)$ & $29(37.2)$ & \\
\hline American Indian/Alaska Native & $3(4.0)$ & $1(1.3)$ & \\
\hline Hispanic & $6(8.0)$ & $4(5.1)$ & \\
\hline $\begin{array}{l}\text { Admission blood glucose, } \\
\text { mean (SD), } \mathrm{mg} / \mathrm{dL}^{*}\end{array}$ & $202.9+1-82.7$ & $186.4+/-89.6$ & .49 \\
\hline Co-morbidities, No. (\%) & & & .81 \\
\hline Cardiovascular & $143(44.1)$ & $152(44.1)$ & \\
\hline Pulmonary & $35(10.8)$ & $21(6.1)$ & \\
\hline Infectious & $30(9.3)$ & $39(11.3)$ & \\
\hline Neurological & $24(7.4)$ & $27(7.8)$ & \\
\hline Gastrointestinal & $15(4.6)$ & $21(6.1)$ & \\
\hline Endocrine & $15(4.6)$ & $16(4.6)$ & \\
\hline Rheumatological & $12(3.7)$ & $10(2.9)$ & \\
\hline Psychiatric & $10(3.1)$ & $13(3.8)$ & \\
\hline Oncology & $8(2.5)$ & $10(2.9)$ & \\
\hline Renal & $7(2.2)$ & $9(2.6)$ & \\
\hline Other ${ }^{\dagger}$ & $25(7.7)$ & $27(7.8)$ & \\
\hline \multicolumn{4}{|c|}{ Routine diabetes medications, No. (\%) } \\
\hline Oral sulfonylurea & $47(62.7)$ & $37(47.4)$ & .06 \\
\hline Biguanide & $21(28.0)$ & $20(25.6)$ & .74 \\
\hline Thiazolidinedione & $11(14.7)$ & $11(14.1)$ & .92 \\
\hline Short-acting insulin & $4(5.3)$ & $7(9.0)$ & .38 \\
\hline Intermediate acting insulin & $25(33.3)$ & $39(50.0)$ & .04 \\
\hline Combination therapy & $32(42.7)$ & $35(44.9)$ & .78 \\
\hline Diet controlled & $5(6.7)$ & $3(3.9)$ & .43 \\
\hline
\end{tabular}

patients with type 2 DM hospitalized for other comorbid conditions. Patients experienced a similar rate of hyperglycemia and hypoglycemia and length of stay regardless of treatment assignment.

These results differ from the nonrandomized study in patients with type 2 DM hospitalized for comorbid conditions and treated with an SSI regimen. ${ }^{11}$ In the report by Queale and colleagues, 76\% of 171 patients were placed on a SSI regimen during hospitalization. When used alone, the SSI regimen was associated with a threefold increase in risk of hyperglycemic events when compared to no standing regimen. Hypoglycemic events occurred in $23 \%$ of the 171 patients studied, and $40 \%$ experienced hyperglycemic events. Since this study was nonrandomized, there is the potential bias that patients with more unstable diabetes were assigned to the SSI regimen and differed from those who continued their routine medications. Our study suggests that when patients are randomly allocated to treatment regimens to avoid assignment bias, there are no differences between the 2 treatment regimens evaluated.

The results of this study suggest that either the addition of the SSI regimen or the use of routine dia-

receiving corticosteroids during hospitalization. In each group, hyperglycemic events were more common than hypoglycemic events. For example, patients receiving intermediate acting insulin experienced a mean of 1.6 hyperglycemic episodes and 0.2 hypoglycemic episodes. Patients with a baseline blood glucose value greater than $250 \mathrm{mg} / \mathrm{dL}$ had a mean of 2.0 hyperglycemic episodes and 0.14 hypoglycemic episodes. Finally, patients using corticosteroids had a mean of 3.9 hyperglycemic episodes and 0.5 hypoglycemic episodes. Other variables (treatment group, admission diagnosis, length of stay) were not significantly associated with glycemic events during hospitalization.

\section{DISCUSSION}

This study demonstrates no benefit from the addition of the SSI regimen to routine diabetes medications in betes medications alone are equally acceptable treatment strategies for managing diabetes in a patient hospitalized for another illness. Clinicians should consider patient preferences in their selection and consider any cost differential in making their treatment decision.

Because SSI regimens require multiple insulin injections during the day that place increased demand on nursing personnel, this approach may be more expensive while not providing any benefit over routine diabetes medications. Physicians should consider the additional nursing time demands and cost implications before routinely ordering SSI coverage for their patients.

In addition to finding no difference in primary outcomes between the addition of an SSI to routine medications and routine medications alone in this study, we also identified 3 risk factors associated with glycemic events. Patients who were using intermediate acting insulin at the time of admission were nearly 


\section{Table 3. Glycemic Control and Length of Stay in Patients Treated with the Addition of the SSI Regimen to Routine Medications or Routine Medications Alone}

\begin{tabular}{|c|c|c|c|}
\hline Outcome & $\begin{array}{l}\text { SSI-plus-routine- } \\
\text { medications group } \\
\text { (n }=75)\end{array}$ & $\begin{array}{l}\text { Routine- } \\
\text { medications- } \\
\text { only group } \\
(n=78)\end{array}$ & $P$ value \\
\hline $\begin{array}{l}\text { Patients with hyperglycemic } \\
\text { episode(s), No. (\%) }\end{array}$ & $25(33.3)$ & $27(34.6)$ & .87 \\
\hline $\begin{array}{l}\text { Patients with hypoglycemic } \\
\text { episode(s), No. (\%) }\end{array}$ & $6(8.0)$ & $7(9.0)$ & .83 \\
\hline $\begin{array}{l}\text { Patients with any glycemic } \\
\text { episode, No. (\%) }\end{array}$ & $27(36.0)$ & $28(35.9)$ & .99 \\
\hline $\begin{array}{l}\text { Mean number of glycemic } \\
\text { events per patient, mean (SD) }\end{array}$ & $1.3(2.9)$ & $1.3(2.5)$ & .99 \\
\hline $\begin{array}{l}\text { Length of hospitalization, } \\
\text { mean (SD) }\end{array}$ & $5.0(4.2)$ & $5.3(5.4)$ & .86 \\
\hline
\end{tabular}

Table 4. Blood Glucose Values in Patients Experiencing Primary Outcomes (hyperglycemia and hypoglycemia)

\begin{tabular}{|c|c|c|c|}
\hline Outcome & $\begin{array}{l}\text { SSI-plus-routine- } \\
\text { medications group } \\
\text { (n }=75)\end{array}$ & $\begin{array}{l}\text { Routine- } \\
\text { medications- } \\
\text { only group } \\
(n=78)\end{array}$ & $\begin{array}{c}\text { Overall } \\
(N=153)\end{array}$ \\
\hline \multicolumn{4}{|c|}{$\begin{array}{l}\text { Blood glucose values in patients } \\
\text { experiencing hyperglycemia }\end{array}$} \\
\hline Mean (SD), mg/dL* & $359(56)$ & $339(28)$ & $349(45)$ \\
\hline Range, mg/dL* & $(203-482)$ & $(299-412)$ & $(203-482)$ \\
\hline \multicolumn{4}{|c|}{$\begin{array}{l}\text { Blood glucose values in patients } \\
\text { experiencing hypoglycemia }\end{array}$} \\
\hline Mean (SD), mg/dL* & $43(7)$ & $42(6)$ & $43(6)$ \\
\hline Range, mg/dL* & $(31-50)$ & $(34-49)$ & $(31-50)$ \\
\hline
\end{tabular}

enrolled in the study. Physicians were not blinded to treatment assignment and were allowed to adjust the regular diabetes regimen during hospitalization in response to patient factors (ie, blood glucose values, new contraindications, side effects, cost, etc). Although these were not specifically monitored during the study, it is possible that medications were changed differently among the 2 treatment groups, and this may have affected the study outcomes. However, this was allowed during the study in order to simulate routine care. Finally, blood glucose control was not assessed in the study (ie, daily blood glucose values), so it is possible that 1 group may have had better blood glucose control during hospitalization. However, there is a lack of evidence to support the benefit of short-term glucose control in diabetic patients with the comorbid conditions enrolled in this study.

Also, it is important to note that this study focused only on patients with type $2 \mathrm{DM}$. Other studies in patients with type $1 \mathrm{DM}$ and DKA found that the use of the SSI alone resulted in higher blood

3 times as likely to have glycemic events during their hospitalization. It is doubtful that the use of intermediate acting insulin led to poorer glycemic control in this group, but rather that the use of intermediate acting insulin was a marker for poorer glycemic control. In addition, patients receiving corticosteroids and those with elevated blood glucose values greater than $250 \mathrm{mg} / \mathrm{dL}(13.9 \mathrm{mmol} / \mathrm{L})$ on admission were also about 7 times more likely to have glycemic events, regardless of the treatment assignment. Consequently, the presence of these risk factors in a diabetic patient admitted for another medical problem should alert the physician that poor glycemic control is likely and might prompt closer monitoring in an effort to avoid complications.

This study is limited in the fact that the population was chosen from a convenience sample, rather than from consecutive patients hospitalized and meeting study inclusion criteria. It is possible that a subset of patients who may have received benefit or been harmed by the use of the SSI regimen were not glucose values and prolonged the duration of hospitalization when compared with regimens including longacting insulin. 7,10 Because our study excluded patients with type 1 DM, the results of our study should not be generalized to these patients. Physicians should also be reminded that patients who were unable to take food or medications by mouth were excluded from the study. Therefore, our results should not be applied to this patient population where the SSI regimen is routinely used. Our results should not be applied to patients with type 2 DM who are critically ill, as these patients were excluded. In addition, our study used a specific SSI regimen, and results may have been different if a more or less aggressive regimen were used.

The use of the SSI regimen in combination with routine diabetes medications does not influence the rate of hyperglycemia or hypoglycemia or change the length of stay in patients with type 2 DM hospitalized for other conditions. Patients receiving intermediate acting insulin as part of their routine diabetes medication regimen, 


\begin{tabular}{|c|c|c|c|}
\hline Variable & $\begin{array}{l}\text { Regression } \\
\text { Coefficient }\end{array}$ & $\begin{array}{l}\text { Standard } \\
\text { Error }\end{array}$ & $\begin{array}{l}\text { Odds Ratio } \\
\text { (95\% Cl) }\end{array}$ \\
\hline Treatment versus control & -0.0802 & 0.4260 & $0.923(0.400-2.127)$ \\
\hline $\begin{array}{l}\text { Use of intermediate acting insulin as } \\
\text { part of routine diabetes medications }\end{array}$ & 1.0150 & 0.4400 & $2.759(1.165-6.536)$ \\
\hline $\begin{array}{l}\text { Admission blood glucose } \\
\leq 180 \mathrm{mg} / \mathrm{dL} \text { vs }>180-250 \mathrm{mg} / \mathrm{dL}\end{array}$ & 0.5107 & 0.5251 & $1.666(0.595-4.664)$ \\
\hline$\leq 180$ vs. $>250 \mathrm{mg} / \mathrm{dL}$ & 1.8457 & 0.5091 & $6.332(2.335-17.174)$ \\
\hline $\begin{array}{l}\text { Diagnosis on admission } \\
\text { Cardiovascular disease }\end{array}$ & -1.0390 & 0.6042 & $0.354(0.108-1.156)$ \\
\hline Infectious disease & 0.4613 & 0.4537 & $1.586(0.652-3.859)$ \\
\hline $\begin{array}{l}\text { Corticosteroid use versus non-use } \\
\text { during hospitalization }\end{array}$ & 2.2057 & 0.5556 & $9.076(3.055-26.969)$ \\
\hline Length of stay & 0.0848 & 0.0502 & $1.088(0.968-1.201)$ \\
\hline
\end{tabular}

versity of Mississippi Medical Center, Jackson, MS, Oralia V. Bazaldua, PharmD, BCPS, University of Texas Health Science, San Antonio, TX

Data collection: Barbara Novak, PharmD, Melanie Sadler, PharmD, Idaho State University, Pocatello, ID; Kam Chan, MD, Self Memorial Hospital, Greenwood, SC; Robin Moorman, PharmD, University of Mississippi Medical Center, Jackson, MS.

Data Entry: Elizabeth W. Blake, PharmD, Medical University of South Carolina, Charleston, SC those with elevated blood glucose values upon admission, and those given corticosteroids during hospitalization may be more likely to have glycemic events. Other measures (ie, use of long-acting insulin and other antidiabetic agents) may be effective in minimizing hyperglycemia and hypoglycemia during hospitalization in patients with type $2 \mathrm{DM}$ and other comorbid conditions.

To read commentaries or to post a response to this article, see the online version at http://www.annfammed/cgi/content/full/1/1/29.

Key words: Insulin, Diabetes Mellitus, Sliding Scale, Inpatients, Endocrinological System/Metabolism

Received January 2, 2003; Accepted March 13, 2003.

Presented as a poster at the North American Primary Care Research Group Annual Meeting, Halifax, NS. October 2001.

\section{Funding support}

Supported in part by the American Academy of Family Physicians/American Academy of Family Physician Foundation Joint Grant Awards Program (G0014)

\section{Acknowledgments}

We wish to thank a number of people who helped with this study:

Study coordinators: Steven T. Eggleston, PharmD, BCPS, Greenville Hospital System, Greenville, SC, Rex W. Force, PharmD, FCCP, BCPS, Idaho State University, Pocatello, ID; Melissa M. Blair, PharmD, BCPS, CDE, Medical University of South Carolina, Charleston, SC, Mark VanSwol, MD, Self Memorial Hospital, Greenwood, SC Steven R. Smith, MS, RPh, BCPS, The Toledo Hospital, Toledo, $\mathrm{OH}_{i}$ Joseph Saseen, PharmD, BCPS and Sheryl Follin, PharmD, BCPS, University of Colorado Health Sciences Center, Denver, CO; Michael E. Ernst, PharmD, BCPS, University of Iowa, lowa City, IA ; Cindy Noble, PharmD, Uni-

\section{References}

1. Katz CM. How efficient is sliding-scale insulin therapy? Problems with a "cookbook" approach in hospitalized patients. Postgrad Med 1991;89:46-48,51-54,57.

2. MacMillan DR. Insulin adjustment by the sliding scale method - a straw man who won't stay down? J Ky Med Assoc 1991;89:211-212.

3. Queale WS, Seidler AJ, Brancati FL. The use of sliding scales in medical inpatients with diabetes mellitus. J Gen Intern Med 1995; 10(4 suppl):47.

4. Paauw DS. Did we learn evidence-based medicine in medical school? Some common medical myths. J Am Board Fam Pract 1999;12:143-149.

5. Shagan BP. Does anyone here know how to make insulin work backwards? Why sliding scale insulin coverage doesn't work. Pract Diabetol 1990;9:1-4.

6. Hirsch IB, Paauw DS, Brunzell J. Inpatient management of adults with diabetes. Diabetes Care 1995;18:870-878.

7. MacMillan DR. The fallacy of insulin adjustment by the sliding scale. J Ky Med Assoc 1970;68:577-579.

8. Lilley SH, Levine Gl. Management of hospitalized patients with type 2 diabetes mellitus. Am Fam Physician 1998;57:1079-1088.

9. Sawin CT. Action without benefit. The sliding scale of insulin use. Arch Intern Med 1997;157:489.

10. Gearhart JG, Duncan JL, Replogle WH, Forbes RC, Walley EJ. Efficacy of sliding-scale insulin therapy: a comparison with prospective regimens. Fam Pract Res J 1994;14:313-322.

11. Queale WS. Seidler AJ, Brancati FL. Glycemic control and sliding scale insulin use in medical inpatients with diabetes mellitus. Arch Intern Med 1997; 157:545-552.

12. Montori VM, Bistrian BR, McMahon MM. Hyperglycemia in acutely ill patients. JAMA 2002;288:2167-2169.

13. Malmberg K, Norhammar A, Wedel H, Ryden L. Glycometabolic state at admission: important risk marker of mortality in conventionally treated patients with diabetes mellitus and acute myocardial infarction: long-term results from the Diabetes and Insulin-Glucose Infusion in Acute Myocardial Infarction (DIGAMI) study. Circulation 1999:99:2626-2632.

14. Van Den Berghe $G$, Wouters $P$, Weekers $F$, et al. Intensive insulin therapy in critically ill patients. N Engl J Med 2001;345:1359-1367.

15. American Diabetes Association. Hospital admission guidelines for diabetes mellitus. ADA Clinical Practice Recommendations 1999. Diabetes Care 1999;22(Suppl 1):S80. 